\section{RETRO-DISPLACEMENTS OF THE UTERUS WITH SOME MODES OF TREATMENT.}

BY JOHN MADDEN, M.D. MILWAUKEE, WIS.

The different opinions which have been and still are held regarding the pathologic importance of the retro-positions of the uterus, together with the many different mechanical and surgical measures employed for their relief, form an interesting and profitable study. The subject is not a new one; and it would seem that a sufficient amount of evidence is already at hand to warrant definite opinions and establish well defined lines of remedial procedure. This, however, is not the case; for one who reads the literature of the subject from the time of Simpson to the present day is liable to be a good deal confused both as to the importance of the condition itself and the value of the different remedies for its relief.

Dr. Simpson's articles on retro-position were published between 1843 and 1848. They were the first extensive observations upon the subject which had yet been published. The prominence of the writer brought out many articles on the subject and his extreme views as to the importance of the displacement had many adherents. Thus we find Ashwell in 1844 making the following observation: "Retroversion is an alarming, but a rare displacement and when fully established the altered position of the uterus is most striking. The fundus is turned downward and backward into the hollow of the sacrum, while the os and cervix are carried upward and forward, impinging on or lying above the symphisis pubis. It is the opposite of anter-version and demands more prompt attention; for although at first, neither the structure nor the function of the organ are affected, if it be overlooked or neglected it will not be long ere extreme irritation and danger ensue." (Ashwell, Ed. 1845, p. 418.) Quoting further from Ashwell (p. 420): "Retroversion is not at the moment of its occurrence, except it happen very suddenly, indicated by any marked change in the patient's state of feeling; she generally remains ignorant of the accident until an attempt is made to relieve the bladder. Failing in this she becomes alarmed and uses straining efforts but is unable to accomplish the act. The distension and the inability continue to increase-and in twenty-four hours if the catheter is not used the suffering will be extremebut the bladder is not the only organ whose functions are interfered with; the rectum is so pressed upon by the fundus of the uterus that constipation and sometimes almost entire suppression of stools ensue." Other symptoms given by the same author are nausea and vomiting, painful fullness in the pelvis, dragging in the loins, and expulsive pains like labor; also stomachic and abdominal pain, fever with quick pulse, hot skin and great restlessness. (Ibid).

Views similar to the above were expressed by Rigby, Protheroe Smith, Henesley and other contemporaries of Professor Simpson. These opinions were antagonized, however, by Drs. Bell and Oldham, but their greatest opponent was Dr. James Henry Bennett who, in 1849, criticized the views of Dr. Simpson's followers in the following language: "There has been a great tendency, of late years, to exaggerate the importance of this displacement. The essays of Dr. Simpson himself, although highly practical and interesting, are not free, in my opinion, from this reproach (Bennett 'On The Uterus,' Ed. 1850, p. 202). I am the more disposed to insist upon the opinions which I entertain upon this subject, as several writers in their attempts to follow Dr. Simpson's researches have published such singularly erroneous statements respecting retro-version of the uterus and its symptoms, that I feel called upon to enter my protest against doctrines calculated to mislead the profession. Thus it is repeatedly asserted that it frequently, if not generally gives rise to all the local, functional and general symptoms and reactions which I have described as characterizing inflammatory affections of the-uterus, to engorgement of the uterine neck, to chronic inflammation of the ovaries. ("Sterility and C.', ibid p. 203). These assertions are stated to be founded upon clinical fact; but I firmly believe that they are, to a great extent, deduced from facts misunderstood or misinterpreted." (Ibid).

Notwithstanding the protests of Bennett and a few others, the views of Simpson seem to have been geverally adopted in England. Previous to Dr. Simpson's publications too, there already existed in Germany and France, quite an extensive literature on the subject of retroversions; and views of their importance as pathologic factors held by the German and French gynecologists did not differ materially from those expressed by the Edinburgh professor. Among those of the German school who wrote of these displacements were Schweighanser, of Strasburg; Bruninghausen, of Wurtzburg; Schmitt, of Vienna; Schneider, of Baldy; and Kirchner, of Poeneck; and of the French the writings of Madam Boivin and Dr. Duges are the most conspicuous. Colombat, the painstaking and conscientious French gynecologist, published his work on the "Diseases of Females" in 1844 (translated by Meigs, Second Ed., 1850). In the preparation of this work, he states in the preface that he has examined the works of over one thousand writers on gynecologic subjects; and as this was more a consensus of opinion rather than a particular dogma of the author, the articie on retro-positions of the uterus is reliable, in that it gives what was probably, the approved teaching at that time. Of the symptoms of retro-version this author writes as follows (Meigs' "Colombat," p. 160161): "Supposing the womb to be non-gravid, and the cavity of the pelvis of ordinary dimensions, if the displacement takes place gradually, the patient begins to feel an inconvenient sense of pressure within the pelvis; then the groins, the loins, and thighs are affected little by little with dragging pains, which become more and more annoying. Soon after this the signs of inflammation of the womb become manifest, and the suffering more acute; the catamenia become disordered, either increasing or diminishing in quantity; a leucorrhea, which in some instances is bloody, flows during the intervals between the menses; the digestion is deranged; the appetite is lost; the woman grows thin and her strength diminishes. At length a fever sets in which in some cases, is of a high grade and continued type; but in others slight, and characterized only by heat of the skin, and by agitated evenings and nights.

"To the above symptoms, there is always added a sense of pressure at the bladder or rectum, giving rise to frequent desire to urinate or go to stool. During the flow of urine the jet is soon checked or suddenly arrested, and as the displacement always increases in proportion to the efforts made to expel 
the urine and feces, the symptoms are always greatly augmented by those attempts." It is needless to point out that in the light of modern pathology, this formidable train of symptoms could not be produced by a mere retro-displacement of the uterus. Here we have an accurate portrayal of infectious invasion of the genital canal, beginning with a vaginitis ard ending with profound pelvic inflammation. A striking example of Dr. Bennett's charge that the symptoms are misrepresented or misunderstood. This subject will, however, be discussed further on in this article.

In America, the extreme views of the importance of retropositions were adopted with little reservation. Meigs, writing in 1850, expresses himself thus: "In my opinion a majority of the cases called womb complaint, met with in this country, are cases of retroverted uterus. An ample experience teaches me that such instances are far more numerous than mere prolapsus. Indeed, a simple prolapsus not gone to the extent of procidentia, does not necessarily give the patient a great deal of distress. A woman soon becomes accustomed to a moderate degree of descent of the organ, and does not feel, or even suspect its existence." He further remarks that the accident is very common in girls who lead a sedentary life. In this class of cases, failure to empty the bladder at proper intervals produces stretching of the round ligaments until they become incapable of acting as uterine supports; and, also that the disease "ought to occur as frequently in the sedentary girl as in the wife and mother." (Meigs" "Colombat," p. 160). Sims and Hodge held similar opinions, and the latter will long be remembered for his extreme views regarding the value of the pessary which still have their influence with gynecologists. Dr. Thomas in 1880 ("Diseases of Women," fifth Ed..pp. 436 and 438) gives the usual long list of symptoms produced by retro-displacements of the uterus. Among the consequences of posterior displacements, he mentions dysmenorrhea, endometritis, sterility, aveolar, hyperplasia, and pelvic peritonitis. "Furthermore," says Dr. Thomas, "the body sometimes descends to the upper extremity of the vagina and instances are recorded by Rokitansky and Schott in which it penetrated the walls of the vagina and rectum, and forced itself into these canals. This is a very rare exception, but it is worthy of mention as showing how great is the pressure which a retroflexed uterus may exert. "As rare complications may be recorded hematometra and hydrometra from imprisonment of fluids by obliteration of the canal by flexion at the os internum."

In Dr. Emmett's article on uterine versions ("Principles and Practice of Gynecology," Third Ed.) an elaborate system of tables is given; but a study of them brings little conviction beyond the fact that inflammatory changes are almost always found in connection with retro-versions.

More recent writers, as a rule, hold practically the same opinions as those already cited. Dr. Geo. S. Harrison, of New York, ("American System of Gynecology," Vol. II, p. 1116) says that "the symptoms of chronic retroversio-flexios are so multiform they embrace the entire gamut of morbid sensations;" and that besides the ills directly referable to the uterus and neighboring organs of which a very long catalogue is given, indeed, "the most varied alienations of the psychical sphere, the strangest forms of anesthesia and hyperesthesia of particular portions of the body, the most persistent forms of neuralyia, and, finally spasm and paresis involving different groups of muscles, may be dependent entirely upon retroversio-flexios and can be partially or completely relieved only by a restoration of the uterus to its normal position." This author says much more in the same strain, but it is not necessary to quote further from his article to show the importance which he gives to retro-displacements as pathologic factors. Pozzi dismisses the subject in a few lines, quoting the views of others without committing himself (Vol. I, p. 438). Skene in his treatise on the diseases of women (p. 308) mentions the common symptoms referable to the pelvic organs, making the reservation, however, that the suffering caused by retroversion varies greatly in different patients and that one of his patients who had retro-version many years, not only suffered no discomfort, but was one of the most active women he had ever known. Prof. August Martin, of Berlin, ("Frauen Krankheiten," p. 90) who mentions the usual symptoms of backache. pressure and dragging down, and vesical and rectal ten. esmus found in connection with retro-positions, makes the following remark: "These appearances which are looked upon as quite particularly characteristic of retroflexions, the reactions upon the nerve plexes on the anterior wall of the sacrum and dependent inability to stand and walk belong more fre. quently, not to the retroflexion as such, but to a perimetritis which exists at the same time, and in these cases generally originates in the same puerperium as the deviation of the uterus, but not caused by it alone." ("Diejenigen Erscheinungen. welche as gans besonders den retroflexion Eigenth ̈̈mlich angesehen werden, die Rückwirkung auf die Nervengeflchte an der Vordern Wand des Kreuzbeines und dadurch beding. tes Unvermögen zu, stehen und gehen, gehören viel haüfiger nicht zu Retroflexion als solche, sondern zu Einer Perimetritis, die gleichzeitig besteht und in diesen Fällen gewöhnlich aus demselben Wochenbett stammt wie die Deviation des Uterus von ihr allein aber nicht verursacht werden".)

I have taken the trouble to examine all such authorities as I have access to and quoted freely from the same in order to show what has been and what now is the generally accepted opinion as to the pathologic importance of retro-deviations of the uterus as such. A consultation of a great number would probably not change the result, as the opinions quoted are those of representative men. From the evidence hore preserited, then, we are to believe that retro-version and retro-flexion may be productive of profound anatomic changes, inflammatory in their character and that they may give rise to symptoms "so multiform that they embrace the entire gamut of morbid sensations."

That a retro-version of a uterus otherwise normal and where the other pelvic organs are in a normal condition of health, can produce even a small amount of discomfort, is difficult to believe. The specific reasons given for the sufferiug caused by the displacement are pressure upon the rectum, producing rectal tenesmus, constipation and other associated ills, and obstruction to the circulation in the uterine body gives rise to uterine congestion, enlargement, metritis and endometritis. also, logically of salpingitis, followed by all the symptoms which these disorders generally produce. In retro-flexions we are to add a greater amount of obstructions, to the 
circulation, by reason of the sharp bend in the uterine neck and also obstructive dysmenorrhea rè. sulting from the same deformity. To convince you of the importance which has been given the pressure of the uterus alone, your attention is called to the cases cited by Dr. Thomas, in which the uterus is said to have penetrated the wall of the rectum and vagina, the pressure being so great as to completely obstruct the circulation in these parts. To impress this lesson upon us, Dr. Thomas remarks that "it is a rare occurrence, but it is worthy of remark as showing how great is the pressure which a retroflexed uterus may exert." (loc. cit.) The possibility of such a disaster from retroflexion would probably not find any believers at the present time, but the influence of such teaching is still with us.

The unimpregnated healthy uterus weighs from one to two ounces. Its supports are so arranged as to admit of very free vertical and antero-posterior movement. Its blood supply is abundant and the vessels are tortuous, admitting a free amount of stretching without encroachment upon their caliber. In perhaps a majority of cases the uterus rests upon the bladder when that organ is empty. When the bladder is moderately distended the uterus assumes an upright position and when extreme distension of

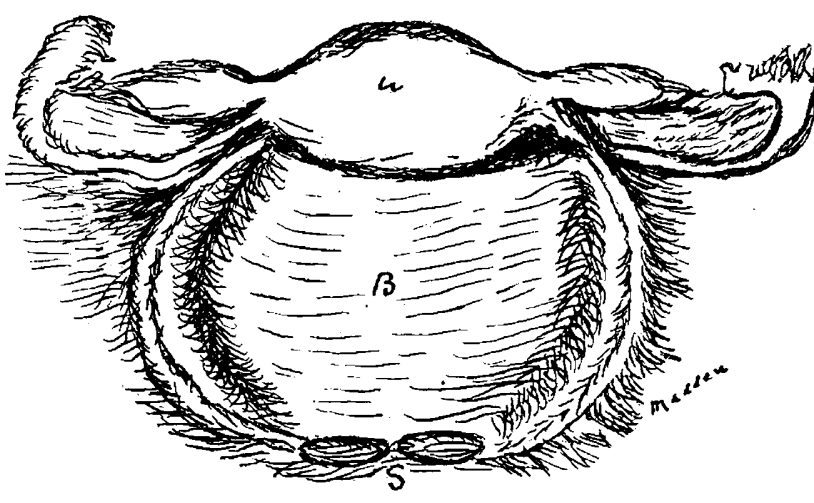

Fig. 1.-Long round ligament and broad vesico-uterine peritoneum, Hllowing free antero-posterior movement of uterus: bladder empty s, मllowing free antero-posterior movement of uterus: bla

the bladder occurs, the uterus may be slightly retroverted. ${ }^{\prime}$ The round ligaments are regarded as the principal agents concerned in holding the uterus in its anterior, "normal," position; but they are frequently poorly developed or altogether absent. (Martin's "Frauen Krankheiten," p. 78). Another important factor concerned in holding the uterus in its anterior position is the extent of the uterine attachment to the bladder, as indicated by the depth of the vesico-uterine cul-de-sac. I have seen this nowhere discussed; but it is well known that the peritoneum in some cases dips deeply down between the uterus and the bladder, closely investing the former organ to or beyond the internal os before it is reflected upon the latter, while in other cases the cul-de-sac is very shallow, both organs being practically covered by the same fold. The importance of this broad stretch of peritoneum must be considerable, probably as great as that of the round ligaments themselves. When, therefore, the round ligaments are absent or only slightly developed, and when at the same time, the vesico-uterine cul-de-sac is deep,

1 This is not true in all cases. Dr. George McClellan, of Philadelphia, found by experiment upon the cadaver that "if the bladder is gradually distended, while the bowel is empty, the fundus is raised until the orga assumes a decided antefiexion." (Regional Anatomy, Vol. ii, p. 113). the uterus will certainly have a greater degree of antero-posterior mobility. It is impossible, under such circumstances that a retroverted uterus could have any pathologic importance, either by reason of its normal weight or that its circulation would be interfered with.

In the case of retro-flexions, excepting where they are congenital, they are probably always preceded by inflammation, usually cervical and corporeal endometritis with elongation and softening of the supravaginal portion of the cervix until it becomes incapable of supporting the enlarged uterine body. Nor is it quite clear how much of the dysmenorrhea met with in retro-flexion is due to the flexion, and how much of the inflammation to the cervical and corporeal endometritis. If the flexion is extreme, so that the axis of the cervix meets that of the body at an acute angle, the mechanical obstruction from this cause alone may, no doubt, be productive of a great deal of suffering. Such extreme cases of retro-flexion are,

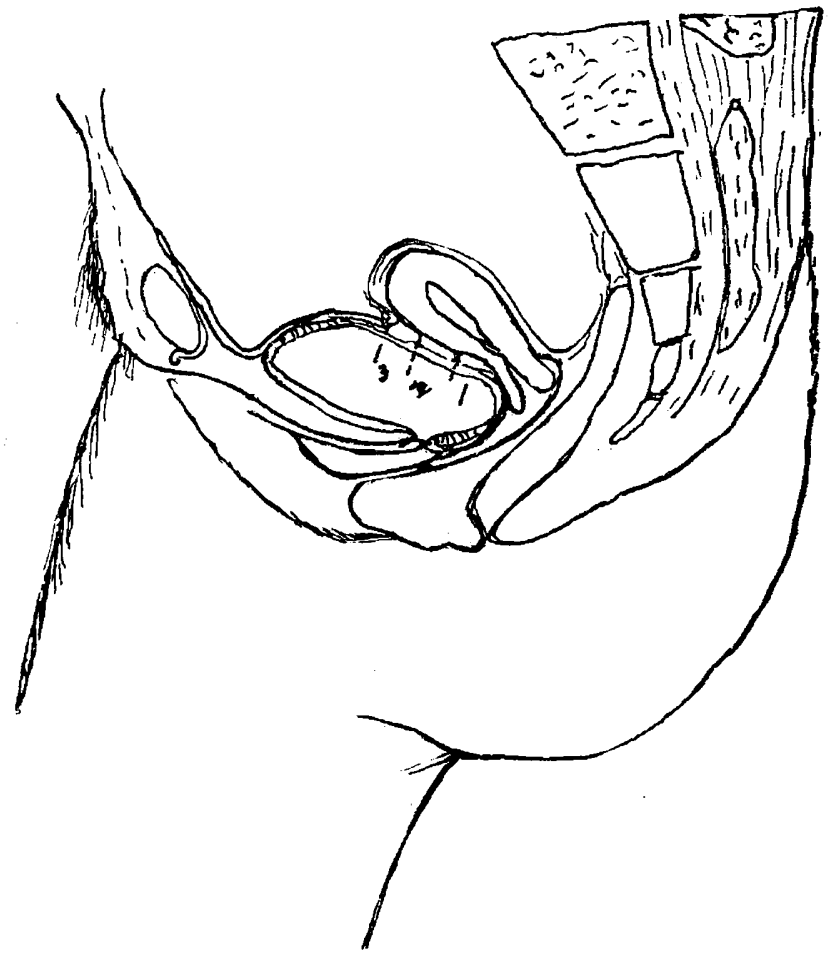

Fig. 2.-Different degrees of attachment between uterus and bladder: $1,2,3$, different depths of vesico-uterine fold. Bladder moderately distended. (Diagramatic.)

however, rare. More often the axis of the uterine canal, at the junction of the cervix and the fundug, describes the arc of a circle with a comparatively long radius, the retro-flexion thus, in itself, not offering any considerable obstruction to the passage of menstrual fluid. This is not the case, however, when the cervical canal is already completely occupied by a redundant mucous membrane, the product of a long continued inflammation. It is not necessary to point out here that an endometritis with the uterus in its normal position may be productive of just as much and just as severe dysmenorrhea as the same inflammation produces when that organ is retroflexed or retroverted. In retro-positions of the uterus, too, especially in retro-flexions, much stress has been laid upon the passive uterine congestion brought about by obstruction of the circulation. Williams, some time ago called particular attention 
to the fact that each segment of the uterus is supplied from a different source, so that flexions could not be productive of obstruction. The fundus uteri receives its blood supply from the ovarian artery, the cervix from the uterine artery. Both vessels, with their accompanying veins, lie between the folds of the broad ligaments, beneath the Fallopian tubes. A mere bending backward of the uterus could not in. terfere with their functions. Let, however, a parametritis take place, an inflammation extending from the tubes to the tissue between the folds of the broad ligaments, and the encroachment upon those vessels with the accompany uterine congestion is easily understood.

What I firmly believe and what I wish to teach is, therefore, that retro-deviation of the uterus is not in itself a pathologic condition; that it is not productive of inflammation; but it is almost exclusively the result of inflammatory process; that the accompanying symptoms are those of the same inflammation when the uterus is not displaced; and that unaccompanied by inflammation, in a normal pelvis, it rarely produces any painful sensation. Exception is to be made in the rare cases of congenital retroflexion, of a high degree, in which obstructive dys.

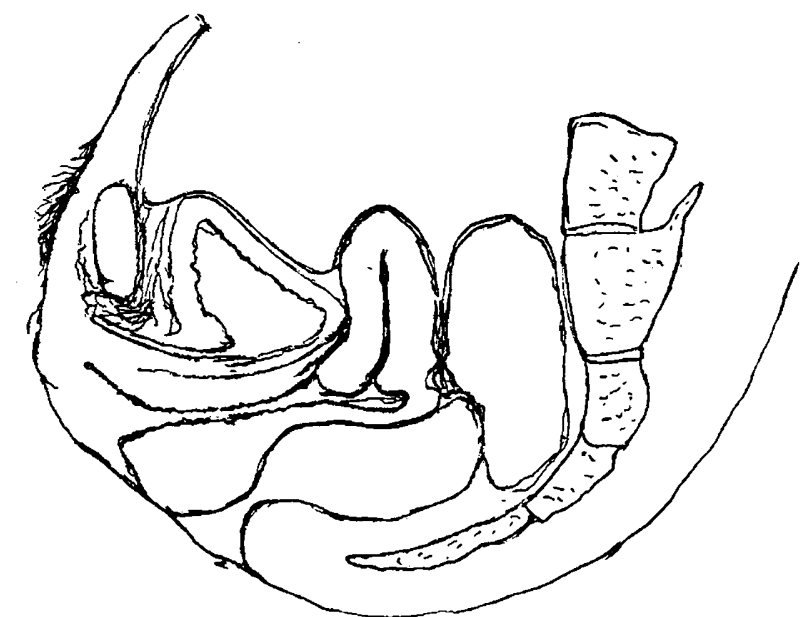

Fig. 3.-Waldeyer's section of frozen cadaver, showing considerable degree of attachment between uterus and bladder.

menorrhea may exist. It is here to be remarked that the evidence of congenital retro-flexion rests upon debatable ground. Martin mentions one case reported by Ruge, but the age of the subject is not given. Schultze and some others seem to covclude that a retro-flexion existing at the time of puberty is to be regarded as congenital. That this conclusion is valid is very doubtful. There is no reason for doubting that hypertrophic changes may take place in the infantile uterus as a result of infectious inflammation of the genital canal, producing cervical elongation and flexion; and that both the inflammation and the flexion remain unrecognized until the age of puberty is reached. Vaginitis and endometritis gonorrheal in their origin, are not extremely rare in young children. I have seen a most violent vaginitis, cystitis, and cervical endometritis in a child 10 years of age, whose father I was then treating for a long standing gonorrhea. I have seen a similar, but less severe, condition in a child 5 years old. In this latter case the disease was of long standing, and the father confessed to having had a gonorrhea nearly two years before.

Retro-deviations of the uterus are productive of no distinctive symptoms. When accompanied by any symptoms at all they are those of inflammation of endometritis, metritis, salpingitis and parametritis. I wish here particularly to mention a condition which is common in retro-displacements of the uterus as well as in inflammatory troubles in which no deviation is present, and which is, I believe, often erroneously attributed to the displacement itself, because relief follows a replacing of the organ in its normal position. I refer to the sensitive point which is found on one or both sides of the uterus, in the region of the Fallopian tube, and within an inch of its entrance into the uterus. There can not be much doubt that this sensitiveness is due to a salpingitis which may exist either alone or in connection with an endometritis. It is located in that part of the tube which suffers a free amount of bending motion during the vertical movements of the uterus; and any remedy which will take the weight of the uterus

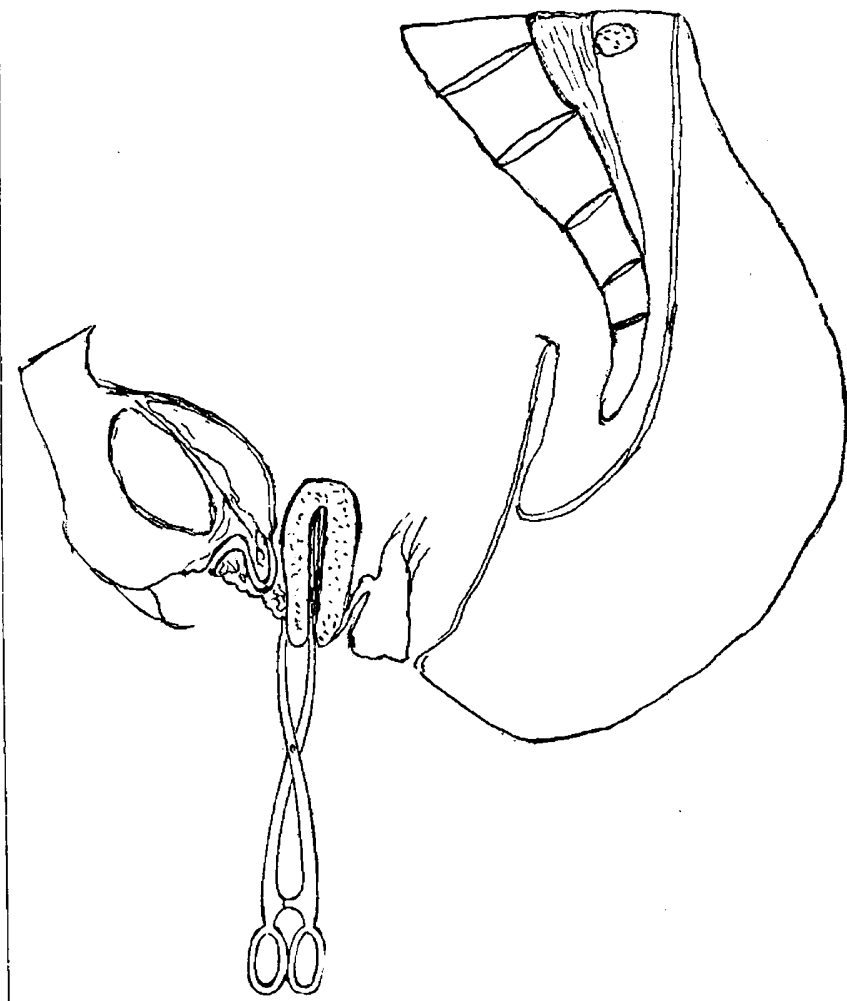

Fig. 4.-Relation of urethra and bladder to uterus when the terus is drawn down. (Diagramatic.)

off the tubes and at the same time limit or abolish its vertical movements will be attended by relief, whether the uterine body is put in its anterior position or not. [ have often seen such relief follow the mere filling of the vaginal vault with cotton, without any attempt made to remedy the retrodisplacement. Where adhesions to Douglass' cul-desac exist, the posterior vaginal vault is sensitive, often exquisitely so; but here the secondary influence of the displacement is too manifest to need discussion.

It is not the purpose of this paper to discuss all the mechanical and surgical measures which have been used for the relief of retro-deviations. The most of them are well known and estimates of their value are as numerous at least, as the men who introduced them. I firmly believe, and this belief is founded upon a considerable amount of experience and observation, that through antiphlogistic and anti- 
septic measures, temporary artificial support of the uterus where the tubes are inflamed, removal of diseased parts with the curette and by proper operations about a lacerated and indurated cervix, and the restoration of an injured pelvic floor together with proper attention to the general nutrition, will relieve all the symptoms attending retro-displacements in a great majority of cases without paying any attention to the deviations as such. Exception is here to be made where the inflammation has been extensive and destructive, where the uterus is firmly bound down by adhesions.

In concluding this article, I wish to mention only three operative procedures for the retention of the uterus in the anterior position: They are ventro-fixation, shortening of the round ligaments by drawing them through the external abdominal ring and the vaginal fixation of Mackenrodt. Ventro-fixation will

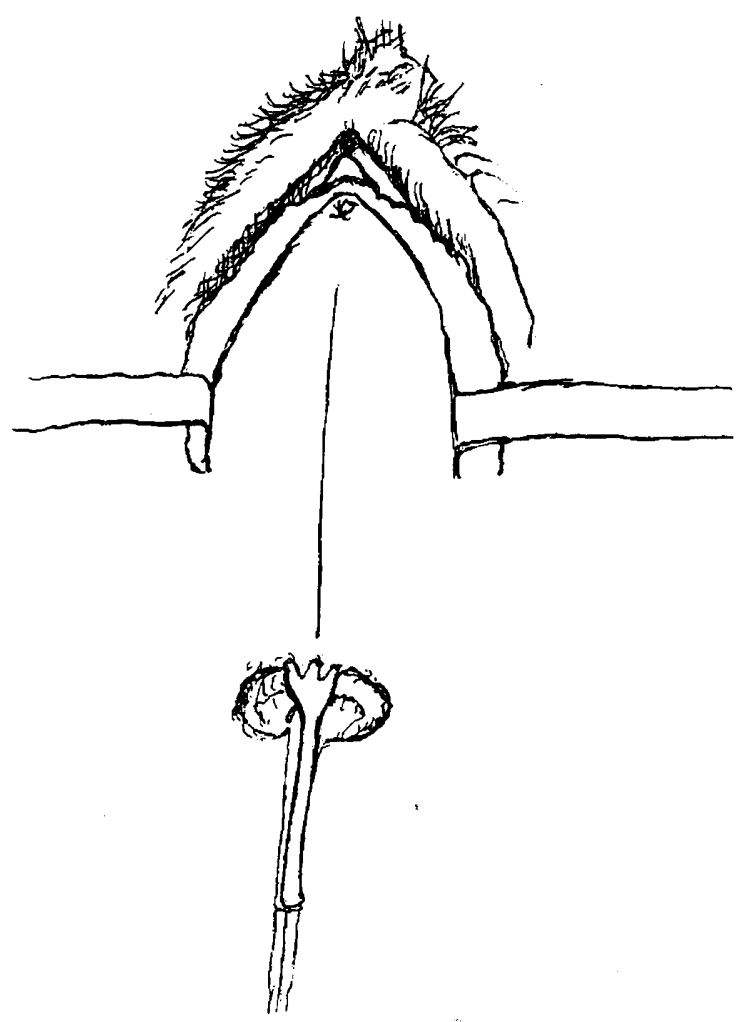

Fig. 5.-First step in Mackenrodt's operation. Uterus drawn down and anterior wall of vagina incised.

probably always be performed in those cases of retroversion in which the opening of the abdominal cavity is a necessity, especially for the purpose of breaking up of posterior adhesions. The value of the operation is not yet established. Martin had performed it forty-three times up to Feb. 1, 1893, thirty-one for posterior adhesions, eight times after the removal of myomata and four times for movable retro-flexions. Since the date here given, he has operated in the same manner a number of times but only for posterior adhesions and after the enucleation of myomata. of the outcome of the forty-three cases here mentioned Professor Martin remarks: "The final results are not brilliant. After one to four years the adhesions of the uterus to the abdominal wall, were so much stretched that the uterus lay free. Sometimes through continuance of the existing perimetritis, the uterus was again brought to the retroflexed position." Only once have I had the opportunity to see the $\theta x$ - tent and strength of the adhesions which may be produced by ventro-fixation. This patient had been castrated by Dr. Christian Fenger, of Chicago, for a myoma about as large as an orange, situated in the left lateral wall of the uterus. A retro-uterine abscess developed for which I opened the abdominal cavity about a year afterward. There were two very firm areas of adhesion, probably aggregating one square inch and apparently capable of sustaining a weight many times greater than that of this very much enlarged uterus. But the tendency of adhesions thus produced, as in all other cases is toward absorption, making a just estimate of the final results of the operation impossible. If, however, the antero-position can be retained only long enough to prevent a readhesion of the uterus should it become again retroverted, the operation has an important place.

Opinions of the value of the so-called Alexander's

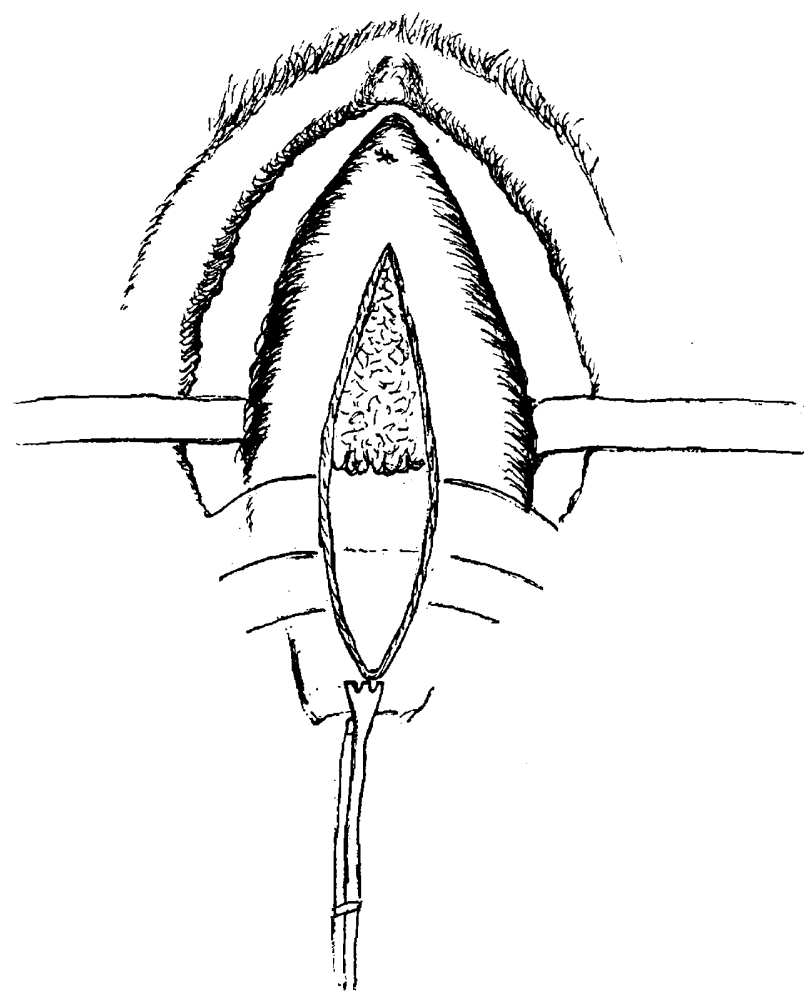

Fig. 6.-Mackenrodt's operation. Vaginal mucous membrane dissected off, sub-mucous tissue pushed up and secured, and three silk sutures in situ.

operation are indefinite and variable. Beyond a few opinions given off hand I have been unable to find any statistical information upon the subject. The operation is suitable for cases not attended by adhesions. The German gynecologists have practiced the operation but very little. Martin remarks: "The inconstancy of the round ligaments, which I have taken the trouble to establish through my laparotomies has to the present, prevented my adoption of Alexander's operation." ("Frauen Krankheiten," p. 98)

In 1892, Mackenrodt, of Berlin, united the body of the uterus to the anterior wall of the vagina for the purpose of correcting retro-deviation of the uterus. The operation has since been performed by other of the German operators, but chiefly by Professor Martin, and as practiced by the latter is briefly as follows: With a combination sound and tenaculum forceps, the uterus is anteverted and drawn downward and 
outward, until the os is quite without the vulva. twice supervened and ran a normal course. MackenWith a scalpel the anterior vaginal wall is then split rodt mentions one normal pregnancy in his cases. It from a point one-third to one-half an inch beneath is quite probable that this operation, like all other the urethral opening down to the portio vaginalis. new operations, will be illy done and overdone. As The mucous membrane is carefully dissected off from a result we shall have much conflicting testimony as the submucous tissue for some distance on either side to its value.

of the incision, the submucous tissue shoved up and its bleeding vessels stilled by several stitches of continued catgut suture. This maneuver leaves the uterine wall bare for the distance of one or two centimeters above the internal os. The vaginal wall is now united directly to that of the uterus by means of three strong silk sutures, the first of which passes through the uterine wall about three-fourths of an inch above the internal os, the second at the internal os, and the third about the middle of the uterine neck. Super-

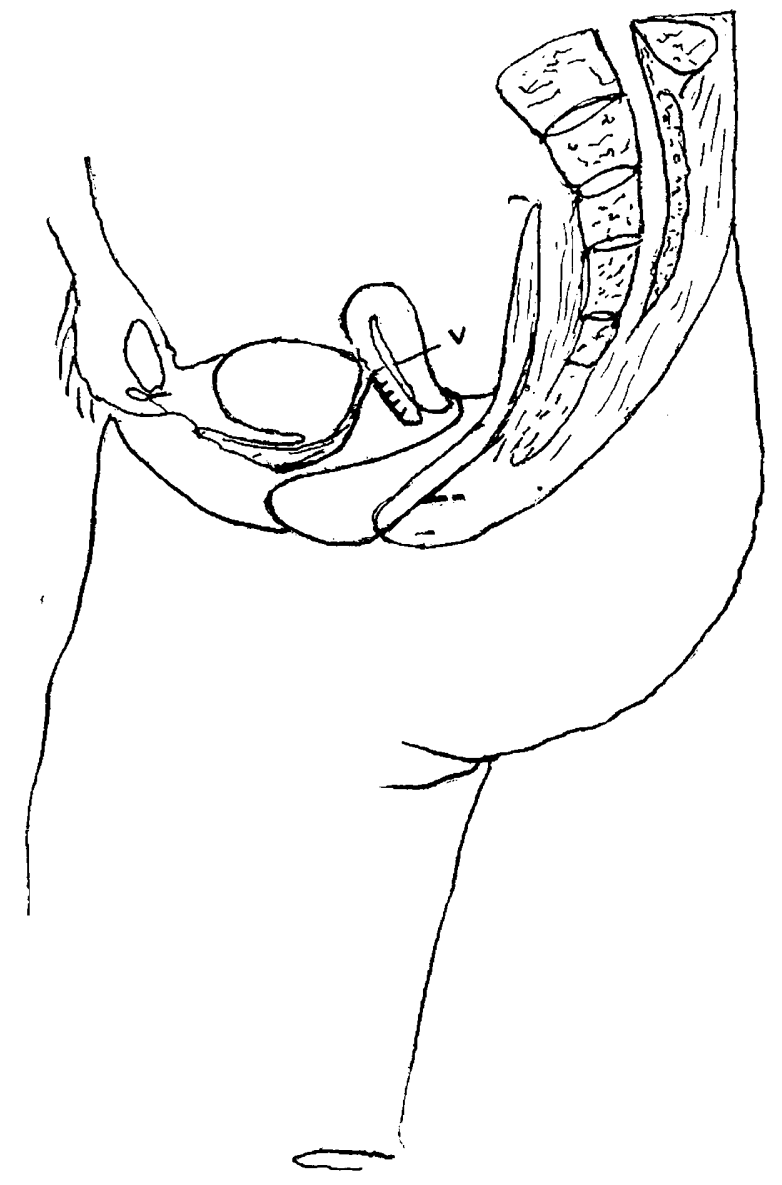

Fig. 7.-Mackenrodt's operation. Sectional view. V, anterior vag. fnal wall bent upon itself and secured to uterus. Upper part of vagina distended.

ficial catgut sutures close the spaces between the silk sutures. The silk sutures are allowed to remain in situ three months. There is no doubt a possibility of injuring the bladder in performing this operation. The injury may be either direct or through subsequent inflammation of the tissue between the uterus and the bladder. I saw in Landau's Clinic, in Berlin, one such case. There was extreme sensitiveness and other evidences of vesical inflammation. The patient had been operated upon by Dr. Vogel several months before.

The operation is new and therefore its value is unknown. Martin has great hopes of its efficiency and In turns upon the significance of the word reaction. The the first thirty of his cases pregnancy afterwardslexpression, irritation or injury, conveys a clearer im- 